\title{
Brígida García Guzmán; breve biografía intelectual*
}

\author{
Marina Ariza**
}

\section{Infancia y temprana juventud}

Brígida García Guzmán nació a finales de los años cuarenta del pasado siglo Xx en la norteña ciudad de Moca, en la región del valle de El Cibao de la República Dominicana. En el memorial de la historia patria que como ésta, toda nación atesora, la entonces pequeña ciudad de Moca $^{1}$ ha sido proverbialmente conocida como tierra de hombres y mujeres bravos y aguerridos, "cuna de presidentes y tumba de dictadores”, pues de ella han surgido al menos tres mandatarios de Estado y más de una generación de ajusticiadores de tiranos, entre ellos el que puso fin a la vida del feroz y sanguinario Rafael Leonidas Trujillo, mejor conocido como el jefe.

Brígida fue la hija mayor de un prominente abogado, Manuel García Lizardo -conocido por su acrisolada rectitud, independencia de criterio y frugalidad, tres veces procurador de la República, presidente de la Junta Central Electoral y embajador en Alemania-, y de una de las pocas mujeres con formación y trayectoria pública de aquel entonces, la educadora y química Acely Guzmán Lora. Pasó su infancia y su temprana adolescencia entre la ciudad de Moca y la capital regional de Santiago de los Caballeros, adonde fue enviada a estudiar en un régimen de internado.

A los 16 años y a instancias de sus padres se trasladó a Michigan, Estados Unidos, para estudiar en una institución educativa dirigida por religiosas donde comenzó su formación de secretaria, oficio visto entonces y ahora como idóneo para cumplir con los roles sociales que debía desempeñar una mujer. Pero quizás por haber visto la luz en la rebelde localidad de Moca o por haber calcado del padre la independencia de espíritu, trascendió el objetivo socialmente prescrito para ella y abrazó la carrera de sociología.

\footnotetext{
* Ciudad de México, 6 de noviembre de 2010. x Reunión Nacional de Investigación Demográfica, El Colegio de México.

** Profesora investigadora del Instituto de Investigaciones Sociales de la UNAM. Correo electrónico: ariza@unam.mx.

${ }^{1}$ De acuerdo con el Censo de Población y Vivienda de República Dominicana contaba en 2002 con 172294 habitantes.
}

$\overline{\text { ESTUDIOS DEMOGRÁFICOS Y URBANOS, VOL. 26, NÚM. } 2 \text { (77), 2011, 501-506 }}$ 
Seis años más tarde, con apenas 22 años de edad, y luego de una breve experiencia como docente en la Universidad Pedro Henríquez Ureña de Santo Domingo, se trasladó a la Ciudad de México para iniciar su formación como demógrafa en El Colegio de México. En esta tierra y en esta institución que tan buena acogida han brindado a la intelectualidad latinoamericana ancló su vida profesional y familiar, pues comenzó su carrera académica y contrajo nupcias con el reconocido economista regiomontano Gustavo Garza. También en esta tierra, de la que se hizo ciudadana y en la que nacieron sus dos hijos, encontró el cariño, la fraternidad y el alter ego intelectual de su compañera de ruta y entrañable amiga, Orlandina de Oliveira.

\section{Vida profesional}

El año 1971 marca el inicio de su fructífera vida profesional; se incorpora entonces como profesora investigadora a El Colegio de México. Treinta y nueve años de entrega a la vida académica son muchos, y si bien ahora no pretendo cansarlos con una relación de la obra de Brígida, me interesa destacar los aspectos que a mi entender imprimen un sello distintivo a su perfil intelectual: la coherencia en sus intereses de investigación, el rigor metodológico, y la lucha por abrir senderos hacia nuevos horizontes analíticos.

En efecto, si fuera a hacer un rápido bosquejo de los temas que incitan su curiosidad intelectual mencionaría en primer lugar su preocupación por los problemas metodológicos, luego su interés por la medición de la participación laboral y los procesos de trabajo, junto a la reflexión acerca de la relación entre el análisis empírico, la construcción de indicadores y la adecuación de los marcos analíticos con que solemos acercarnos a la complejidad del mundo laboral. Esta consistente línea de reflexión se observa en los muchos textos -iniciando con su tesis de maestría-, en que Brígida rastrea con actitud vigilante una a una las implicaciones del cambio en los marcos conceptuales de las encuestas sobre las estimaciones habituales del mundo del trabajo. Desde mi punto de vista el segundo gran núcleo temático de su biografía intelectual es la evolución de los mercados laborales en economías como las nuestras, con históricos problemas de absorción laboral, enfrentadas desde hace décadas a los imperativos de la reestructuración económica y de la globalización, y a los vaivenes de la inestabilidad económica. La preocupación por la absorción laboral en 
las economías periféricas y de insuficiente desarrollo capitalista, como la mexicana, fue precisamente el objeto de reflexión de su tesis de doctorado (1988). Conforme se ha hecho más compleja la realidad del mundo del trabajo por el embate de procesos que favorecen la pérdida de calidad de los empleos y el florecimiento de formas atípicas de inserción laboral, Brígida ha llamado insistentemente la atención sobre la caducidad de algunos de los indicadores con que analizamos los mercados de trabajo y ha promovido con ahínco el desarrollo de nuevas nociones conceptuales y herramientas empíricas. Dos avenidas paralelas se desprenden de esta segunda preocupación central: 1) el interés por la inserción y participación económica de la mujer y sus implicaciones sobre la condición de ésta; 2) la participación laboral de los hogares urbanos como unidades de producción y reproducción en contextos de cambio demográfico. En la primera de estas dos avenidas, Brígida nos ha brindado, hito con hito, una relación puntual de las transformaciones de la participación y de la inserción económica femeninas desde el momento mismo en que esta tendencia se reveló como uno de los aspectos centrales en los mercados de trabajo urbanos del último cuarto del siglo Xx. Desde la segunda avenida nos ha rendido cuentas pormenorizadas de la participación económica diferencial de los distintos integrantes de la familia según su pertenencia de género o de clase, y de los matices y altibajos que su incursión laboral adquiere en un escenario demográfico cambiante. Esta aproximación forma parte de una dimensión de la investigación empírica hoy día algo olvidada, que puede considerarse una de las aportaciones clave de la sociodemografía mexicana a la investigación latinoamericana: la insistencia en el carácter mediador de la unidad doméstica en los procesos de reproducción social. Un libro que retoma esta mirada analítica es Hogares y trabajadores en la Ciudad de México (1982), que escribió en colaboración con Humberto Muñoz y Orlandina de Oliveira.

La tercera línea de reflexión de su producción académica, no por ello menos importante, se ocupa de la familia y las relaciones de género, con especial atención en la dinámica y la estructura familiares y la violencia doméstica. Sin temor a equivocarme puedo afirmar que dos de sus obras, Trabajo y vida familiar en México (1994), y Las familias en el México metropolitano: visiones masculinas y femeninas (2006), ambas en coautoría con Orlandina de Oliveira, son trabajos de consulta obligada en el subcampo de la sociodemografía nacional. Desde muy temprano Brígida formó parte del grupo de destacadas investigadoras nacionales 
que -siguiendo los esfuerzos pioneros de Lourdes Arizpe y Teresita de Barbieri-, asumieron con determinación la bandera de la necesidad de apertura de horizontes en la reflexión sociológica y demográfica para incluir a las mujeres, a esa otra mitad de la población hasta entonces velada por el sesgo androcéntrico, como objeto de investigación con derecho propio. Huelga decir que no han sido pocos los obstáculos que ha sido preciso salvar en este terreno. Fue en parte por esta tesonera labor que se hizo acreedora en el año 2003 del Premio de Población "Luisa María Leal Duk" que otorga el Foro Nacional de Mujeres y Políticas de Población.

Junto a una larga lista de connotadas estudiosas nacionales que sería prolijo enumerar, Brígida contribuyó a desideologizar la aproximación analítica al mundo familiar para dejar al descubierto las múltiples tensiones y contradicciones que encierra el más privado de los ámbitos sociales. Este esfuerzo fue redoblado por la labor de organizaciones feministas de diverso cuño que casi simultáneamente emprendieron una lucha irrenunciable por los derechos de las mujeres. El resultado es que hoy día, entrado ya el siglo XXI, no es posible sostener sin más una mirada ingenua de los procesos y las contradicciones que rigen la vida intrafamiliar.

En su empeño por tender puentes hacia otras perspectivas analíticas, una de sus más recientes consignas ha sido aproximar dos campos en cierto modo ajenos: el de los estudios de pobreza y el de los de mercados de trabajo, en el entendido de que el diálogo entre ambos debe partir del reconocimiento de que en sociedades como las nuestras, donde el Estado de bienestar es prácticamente inexistente, el trabajo es el principal recurso para salir de la pobreza, aunque a veces no por mucho trabajar se deje de ser pobre. ¿Por qué no intentar entonces enlazar con una mirada comprensiva los procesos que vinculan la inserción laboral con la carencia de los satisfactores básicos, a pesar de las distancias que median entre las tradiciones académicas de que se nutren?

Su labor como formadora de nuevas generaciones de estudiosos de la demografía, los mercados de trabajo y la familia, es sin duda uno de los legados más perdurables de su larga trayectoria académica. En parte por la vocación latinoamericanista de El Colegio de México, la simiente de su trabajo pedagógico se ha venido esparciendo por varios países de nuestra región. La tarea de formación de recursos humanos es una de las obligaciones ineludibles de nuestra profesión, pero en pocas ocasiones se emprende con el genuino interés por aquellos a quienes se forma, con sentido de entrega y compromiso. 
Brígida encarna una de esas ocasiones. Al evocar a petición mía su ejercicio magisterial, una de sus exalumnas expresa:

Conocí a Brígida García y comprendí que el esfuerzo de formar nuevas generaciones de profesionales debe trascender los programas curriculares y las aulas de clases. Brígida es con toda seguridad "una maestra por vocación”. De ella destaco valores como el respeto por los estudiantes y el trabajo de los demás, el apoyo a los más vulnerables, la exigencia del rigor científico, la humildad para transmitir el conocimiento, y sobre todo, su gran congruencia entre lo que piensa y transmite.

En forma algo jocosa, otra exalumna comenta:

Me gustaría narrar la forma en que Brígida te dice que lo que entregaste no es lo que esperaba. Varias veces llegué a su cubículo para recibir comentarios de los avances de tesis de maestría que le había entregado; Brígida elegantemente me decía: "este documento tan interesante lo vamos a trabajar después, por ahora vamos a centrarnos en lo que estamos buscando con tu tesis, seguramente lo recuperaremos en algún momento, pero ahora lo vamos a guardar". Ese documento nunca fue recuperado porque en realidad no servía para nada, pero yo salía con la idea de haber hecho algo muy valioso e interesante y entonces me ponía a trabajar en lo que era importante, la tesis.

Estos dos testimonios, que por ahora dejo en el anonimato, son elocuentes acerca de esta faceta de su actividad profesional, que ha alcanzado hasta ahora alrededor de 50 cursos impartidos. Al respecto he observado con atención la feliz combinación entre intuición y pragmatismo que le permiten aquilatar rápidamente lo que cada estudiante es capaz de dar, y dentro de esas lindes, más o menos amplias o más o menos estrechas, conducirlos con éxito para que obtengan el grado académico correspondiente.

A la par de su producción científica y de su ejercicio docente, Brígida ha desarrollado una importante tarea de promoción y consolidación de la institucionalidad en el campo de la investigación sociodemográfica al abrazar con entusiasmo la formación y el crecimiento de varias agrupaciones gremiales, desde la Comisión de Población y Desarrollo del Consejo Latinoamericano de Ciencias Sociales, el Programa Latinoamericano de Actividades de Población, hasta la Asociación Latinoamericana de Población y la Asociación de Estudios del Trabajo, incluyendo a la propia Sociedad Mexicana de Demografía que 
hoy nos convoca, de cuya presidencia se hizo cargo en el periodo 19941996. Igualmente significativa ha sido su participación en órganos colegiados, comités académicos y grupos de trabajo de alcance nacional e internacional. Su compromiso público con la agenda del quehacer demográfico queda de manifiesto en las múltiples instancias de interlocución entre la academia y las instituciones de producción de información y de generación de medidas de acción pública de las que ha formado parte. Y es que su deseo de contribuir a plasmar en iniciativas concretas las implicaciones derivadas del saber demográfico ha dejado al descubierto la fuerte voluntad de congruencia entre el ser y el hacer que la distingue.

Con lo dicho hasta ahora se muestra en forma concisa el perfil académico y humano de Brígida García. Sólo he de añadir, para terminar, una nota personal en virtud de mi relación de amistad con ella. Más allá de la solidaridad incondicional que me ha brindado en momentos difíciles de mi vida, de la que le estoy infinitamente agradecida, siempre he visto con admiración el enorme respeto que prodiga a los demás, respeto que la mueve a tratar de entender primero por qué alguien actúa de determinada manera, por reprobable que sea esa acción, sin mostrar jamás el menor asomo de una expresión peyorativa.

Por eso me es muy grato el día de hoy reconocer públicamente, en nombre de la Sociedad Mexicana de Demografía, la valiosa contribución de esta gran científica social mexicana al fortalecimiento de la disciplina y a la formación de varias generaciones de demógrafos latinoamericanos. 